\title{
AN ASSESSMENT OF PARAMETERS DESCRIBING THE RESPONSE OF A REINFORCED CONCRETE BEAM
}

\author{
J.M. Ingham ${ }^{1}$, D. Liddell ${ }^{2}$ and B.J. Davidson ${ }^{3}$
}

\begin{abstract}
This paper outlines the background to a variety of parameters that are considered in order to establish their suitability as performance descriptors. This assessment is made in conjunction with data collected from twelve tests on nominally identical beam plastic hinges that were tested using different loading histories. Candidate descriptors are categorised as those that consider displacements and those based on damage. A suite of damage indices is also considered. Preliminary comments are made regarding the response comparison of tests conducted using different loading histories.
\end{abstract}

\section{INTRODUCTION}

A companion paper (Ingham et al. 2001) outlined the rationale, test methodology, and salient results from testing of twelve reinforced concrete beams. These beams were nominally identical, but were tested using twelve different loading histories consisting of: laboratory procedures common in the United States, Japan and New Zealand; fabricated histories including monotonic, fatigue, and uni-directional response; and simulated earthquake load histories.

This paper reviews previous research considering the influence of loading histories on the performance of reinforced concrete structures and provides details explaining generation of the simulated earthquake loading histories employed in this study. It also outlines the background to candidate performance descriptors, and assesses the suitability of these descriptors in reflecting the observed condition of the twelve beams.

One reason for identification of the most suitable performance descriptors is to establish an analytical platform that would permit transparent assessment or comparison of tests conducted using unfamiliar or dissimilar load histories. It is suggested that a better understanding of the influence of loading histories on the performance of reinforced concrete structures would assist in the exchange and assimilation of international research findings.

\section{PREVIOUS STUDIES CONSIDERING LOADING HISTORIES}

\subsection{New Zealand Loading History}

In 1989, Park presented a paper on the evaluation of ductility of structures and structural assemblages from laboratory testing. As Park's recommendations have been adopted in New Zealand, it follows that this work forms the benchmark for the current investigation, with Park's recommendations hereafter referred to as the New Zealand loading history (See Fig. 1). Furthermore, the failure condition recommended by Park was adopted throughout this study. A test unit is defined as failing when its peak strength during a cycle drops to below $80 \%$ of the maximum value previously recorded in that quadrant.

\subsection{Alternative Laboratory Loading Histories}

A review of recently published literature from the United States reveals that the laboratory procedure adopted in New Zealand has not been widely employed elsewhere. There are numerous examples of projects published through the United States' 'National Centre for

\footnotetext{
' Cement and Concrete Association Fellow, Department of Civil and Environmental Engineering, University of Auckland, Auckland (Member)

2 Design Engineer, Connell Mott MacDonald Ltd, Auckland (Member)

${ }^{3}$ Department of Civil and Environmental Engineering, University of Auckland, Auckland (Member)
} 


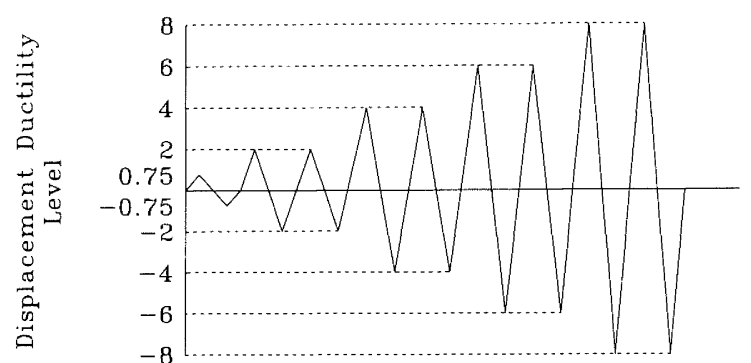

Figure 1: New Zealand Loading History (Park 1989).

Earthquake Engineering Research' (NCEER) that apply loading histories different to the New Zealand loading history.

One of the more prominent earthquake engineering journals in the United States is 'Earthquake Spectra Professional Journal of the Earthquake Engineering Research Institute'. This journal contains numerous examples of recent projects where the loading histories differ from the New Zealand loading history. Possibly most telling is that in February 1996, 'Earthquake Spectra' contained a theme issue on experimental methods. In this issue, Krawinkler (1996) from Stanford University, California published "Cyclic Loading Histories for Seismic Experimentation on Structural Components". Krawinkler discussed the selection of suitable loading histories for laboratory testing based on the number and magnitude of inelastic excursions. However, Krawinkler made no reference to the New Zealand loading history.

Of particular note is the recent coordinated TCCMAR and PRESSS research studies, which have both involved a considerable number of US institutions and employed a common sequentially phased loading history (Porter and Tremel, 1987). As shown in Fig. 2, the loading regime in the TCCMAR and PRESSS programmes was different to the New Zealand loading history. Liddell (2000) has similarly reported on numerous European seismic structural testing studies where the New Zealand record was not considered. Hence, it has been established that the loading procedure adopted in New Zealand differs from that commonly used elsewhere.

\subsection{Effect of Loading History on Experimental Results}

In their report on the evolution of quasi-static testing, Leon and Deierlein (1996) concluded that the selected load history could have a significant effect on experimental results. This was evident in the results from tests where a progressive increase in deformation levels was applied in contrast with large deformations being followed by smaller cycles.

Several researchers have considered the use of multiple loading histories. Lefas and Kotsovos (1990) from the Imperial College of Science and Technology, London conducted studies on reinforced concrete shear walls to determine the effect of using different loading histories and repair methods. They concluded that the strength and

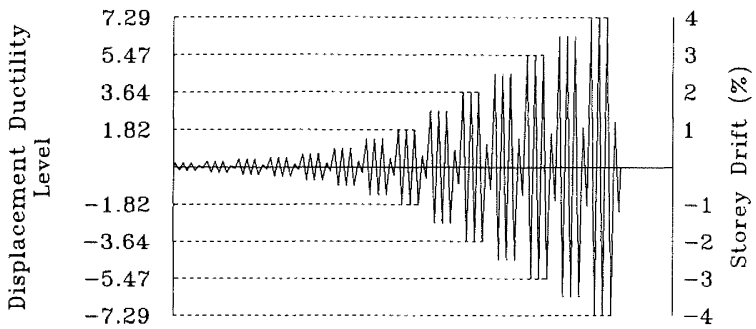

Figure 2: PRESSS Loading History.

deformational response of the original specimens were independent of the cyclic loading regime. Of the repaired walls, the wall subjected to monotonic loading had greater load capacity than the walls subjected to cyclic loading. However, it was found that there was little difference between the results from different cyclic loading regimes.

Hwang and Scribner (1984) from Sargent and Lundy Engineers and the University of Illinois conducted research on reinforced concrete beams to determine the effect of variations in loading histories. They concluded that while the size of the displacements was closely related to strength and stiffness degradation, the actual sequence in which large and small displacements were applied did not have a significant effect on the results. Hwang and Scribner also concluded that any estimation of the energy dissipation capacity of a member must take into account the displacement history.

Tomazevic and Lutman (1996) from the National Building and Civil Engineering Institution in Slovenia conducted 32 tests on identically reinforced masonry walls under four contrasting loading histories: monotonic loading, two different cyclic loading histories, and simulated response of a masonry building during earthquake excitation. Experimental results aided in the development of correlation factors between the monotonic and cyclic hysteresis envelope curves, as well as stiffness and strength degradation parameters.

Tomazevic and Lutman referred to earlier work published by Tomazevic et al. (1996) regarding the influence of different loading histories on test results. Tomazevic et al. observed that strength and stiffness degradation took place when the walls were subjected to repeated cyclic lateral load reversals, and that the maximum lateral resistance attained in the case of monotonic loading was much greater than corresponding values obtained by cyclic loading.

Studies on the influence of loading history have also been conducted in Japan. Kinugasa and Nomura (1992) from the Science University of Tokyo subjected five nominally identical beam units to different cyclic load histories. They proposed a new failure mode based on the accumulation of strain in the hinge zone as the member dissipated energy. It was concluded that the strain accumulation behaviour of a hinge zone was closely related to the type of loading history. Shimazu and Mollick (1991) from Hiroshima University subjected 
frame structures to four different loading histories and noted that "the hysteretic response characteristics are different under different lateral loading programmes in respect of strength deterioration".

In 1994, Kawashima (1994) of the Public Works Research Institute in Japan, published a paper outlining the seismic design of bridges. In his paper Kawashima noted that in reinforced concrete piers, the rupture of main reinforcement due to inelastic load reversals was strongly related to low cycle fatigue of the reinforcement. Kawashima concluded that the number of load reversals at each ductility level was an important factor for controlling damage levels and that damage that developed in the shake table test was much smaller than that developed in the step-wise increasing loading test.

Kunnath et al. (1997) from the University of Central Florida and the National Institute of Standards and Technology in Maryland subjected twelve identical small-scale bridge columns to different pseudo-static displacement histories representing both benchmark tests and predicted earthquake displacement records. Among other objectives this testing was conducted to determine whether the energy capacity of a member was dependent or independent of the applied load history. Notably, there was a total absence of reference to typically adopted load histories worldwide, and while it was determined that the energy capacity of a member at failure is strongly path (history) dependent, no conclusions were made about the relevance of particular loading regimes.

\subsection{Energy Concepts}

In his paper on the evaluation of ductility of structures and structural assemblages from laboratory testing, Park presented a thorough discussion of the issues associated with the determination of structural ductility demand and capacity. Park noted the need for agreement regarding definitions of yield and ultimate displacement so that performance obtained from analytical and experimental investigations can be properly assessed and compared.

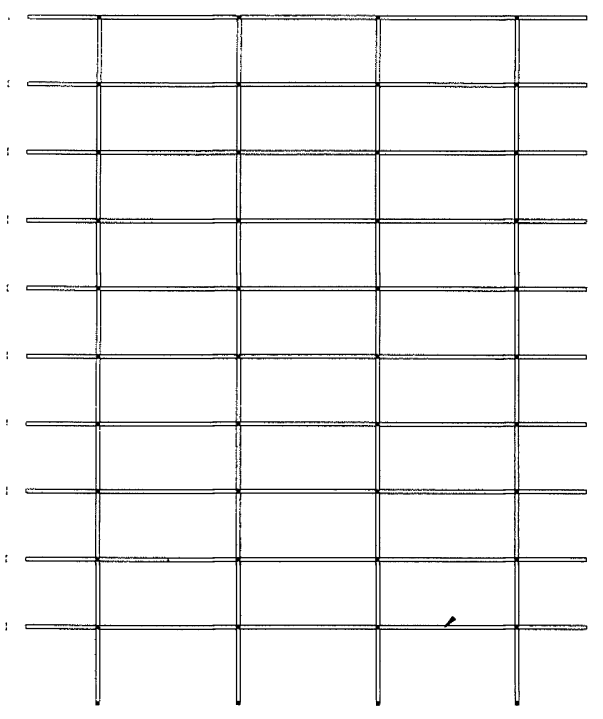

Figure 3: Model Dimensions.
To overcome this difficulty, researchers have proposed using energy concepts as a means of comparing experimental studies.

In the Earthquake Spectra theme issue on experimental methods, Krawinkler stated that cumulative damage concepts have to be utilised to assess performance and that loading histories in experiments must account for the history dependence of seismic performance. Krawinkler observed that the level of damage depended not only on the maximum deformation, but also on the history of deformations that the component undergoes before and after occurrence of the maximum deformation. The number of inelastic excursions and the magnitude of each excursion were found to be dependent on, among other variables, the period of the structure. In his paper Krawinkler made recommendations, taking into account the period of the structure, regarding the number of inelastic excursions in loading histories.

Exercises have also been conducted to correlate the performance of reinforced concrete beams with contrasting detailing and tested by different researchers using a diverse range of loading regimes. For instance, Gosain et al. (1977) compared a number of tests reported in the literature and established a 'work index'. This work index was a measure of the energy absorbed at the hinging region during the loading history and accounted for the severity of the loading. Gosain et al. developed their work index taking into account the member geometry and strength, but not the actual load history. To obtain a more accurate measure of member response to cyclic loading, Darwin and Nmai (1986) extended Gosain's research by establishing an 'energy dissipation index' for different structural details, that took into account the influence of different loading histories.

Fang et al. (1994) used the aforementioned reports and a study by Scribner and Wight (1980) as a basis for an investigation of the strength and ductility of short highstrength concrete ( $\geq 60 \mathrm{MPa}$ ) beams with low flexural reinforcement ratios. Fang et al. considered a total of seven loading histories. It was concluded that the degradation in strength and stiffness varied with the type of loading history applied to the specimen and that the type of loading history influenced the energy dissipation characteristics of the subassemblies.

\section{Earthquake Load History Development}

As part of this study, a model of a ten-storey building was generated in the computer programme Ruaumoko (Carr 1998) in order to generate five simulated earthquake loading histories. The building was modelled at twothirds scale for four of the five acceleration histories to comply with the adopted scale of structural testing (Ingham et al. 2001).

Four different structural elements were defined in the Ruaumoko model. Fig. 3 and Table 1 present summary details of the two-thirds model of the ten-storey building. Beams were modeled as a one component (Giberson) member and the stiffness of the hinge was controlled by 
Table 1: Summary of Frame Properties.

\begin{tabular}{|c|c|}
\hline$T_{1}(\mathrm{~s})$ & 2.226 \\
\hline $\mathrm{T}_{2}(\mathrm{~s})$ & 0.707 \\
\hline $\mathrm{I}_{\mathrm{b}}\left(\mathrm{mm}^{4}\right)$ & $1.28 \times 10^{6}$ \\
\hline $\mathrm{I}_{\mathrm{c}}\left(\mathrm{mm}^{4}\right)$ & $3.32 \times 10^{6}$ \\
\hline $\mathrm{E}_{\mathrm{c}}(\mathrm{MPa})$ & 29200 \\
\hline Mass of Roof Level $(\mathrm{kN})$ & 1609.2 \\
\hline Mass of Typical Level $(\mathrm{kN})$ & 1472.65 \\
\hline Mass of First Level $(\mathrm{kN})$ & 1490.1 \\
\hline Rigid End Zone $(\mathrm{mm})$ & 300 \\
\hline
\end{tabular}

the tangent stiffness of the current point of the Modified Takeda hysteresis rule, adopting $\alpha=0.42, \beta=0.90, r=$ 0.035 , and the reloading stiffness power factor equal to 1.0. The unloading curve proposed by Emori and Schnobrich (1978) was used.

The first floor columns were modeled as beam-column members using the elasto-plastic hysteresis model, whereas columns located on floors two through ten used the linear-elastic model. A yield interaction surface was provided for the first storey columns.

Joints were modeled as fully rigid. This was consistent with experimental behaviour where strain penetration into the joint was suppressed by additional reinforcement. The floor was modeled as a rigid diaphragm.

Experimental data from testing using the New Zealand loading history and from monotonic loading were used to model strength degradation, to determine the length of plastic hinges, and to calibrate damage indices. Consistent behaviour was obtained by setting strength degradation to begin at ductility 6.8 .

The length of the plastic hinge zone was established using measured experimental data from testing using the

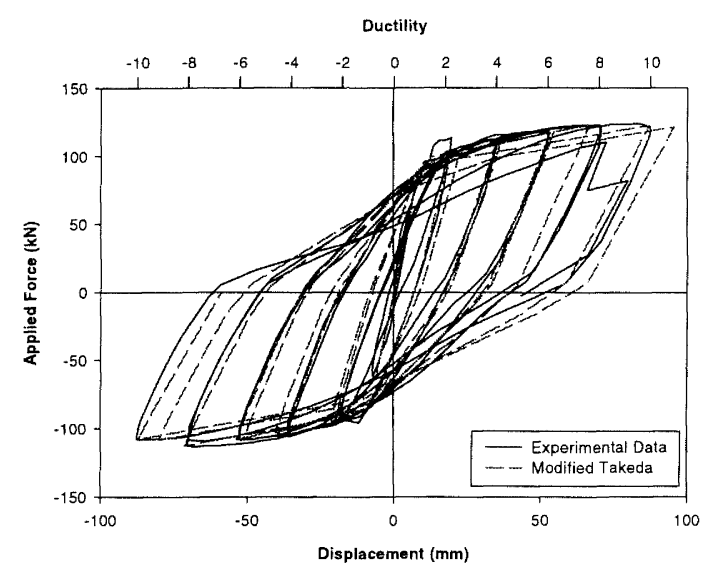

Figure 4: Comparison of Experimental Data and Takeda Model.

New Zealand loading history and formulae published by Paulay and Priestley (1992).

Fig. 4 presents a comparison of hysteresis behaviour from testing using the New Zealand loading history and the Modified Takeda model. It can be seen that there was excellent agreement until ductility six and reasonable agreement thereafter.

The model applied Rayleigh damping and used the initial stiffness matrix, with 5\% of critical damping specified for modes one and ten. This ensured that the fraction of critical damping was less than $100 \%$ for the highest modes. The model applied the lumped mass matrix and used the Newmark constant average acceleration method. The time step for the analysis was chosen to be $0.01 \mathrm{~s}$. Pdelta effects were ignored.

Four separate earthquake acceleration records were applied sequentially at differing scales and in various orders to generate five simulated acceleration histories. At the end of each record, approximately 10 seconds of

Table 2: Earthquakes Records Selected for Generating Acceleration Histories.

\begin{tabular}{|c|c|c|c|}
\hline Earthquake & Acceleration Record & Recording Station & PGA (g) \\
\hline Normalised El Centro & Artifical Earthquake & 0.36 \\
\hline Northridge & Pacoima Dam & & 1.28 \\
\hline El Centro NS & & Imperial Valley & 0.35 \\
\hline
\end{tabular}


Table 3: Summary of Five Earthquake Histories.

\begin{tabular}{|c|c|c|c|c|}
\hline Acceleration History & Event & Earthquake & Scale Factor & PGA (g) \\
\hline A & 1 & Normalised EI Centro & 1.10 & 0.39 \\
& 2 & Northridge & 1.00 & 1.28 \\
& 3 & El Centro NS & 2.00 & 0.70 \\
& 4 & Kobe EW & 1.61 & 1.02 \\
\hline B & 1 & Normalised EI Centro & 1.10 & 0.39 \\
& 2 & Northridge & 1.20 & 1.54 \\
& 3 & El Centro NS & 1.00 & 0.35 \\
& 4 & Kobe EW & 1.20 & 0.76 \\
\hline C & 1 & Normalised El Centro & 1.10 & 0.39 \\
& 2 & Kobe EW & 1.20 & 0.76 \\
& 3 & Northridge & 1.20 & 1.54 \\
& 4 & El Centro NS & 1.00 & 0.35 \\
& 5 & Kobe EW & 1.50 & 0.95 \\
\hline D & 1 & Northridge & 1.20 & 1.54 \\
& 2 & El Centro NS & 1.00 & 0.35 \\
& 3 & Normalised El Centro & 1.10 & 0.39 \\
& 4 & Kobe EW & -1.20 & 0.76 \\
& 4 & Kobe EW & 1.50 & 0.95 \\
\hline E & 5 & Northridge & 1.20 & 1.54 \\
& 1 & Kobe EW & 1.20 & 0.76 \\
& 2 & El Centro NS & 1.00 & 0.35 \\
& 3 & Normalised EI Centro & 1.10 & 0.39 \\
& 3 & Kobe EW & 1.50 & 0.95 \\
\hline
\end{tabular}

free vibration was applied. This was to ensure that the building was at rest before the next record was applied and also to give an indication of the viscous damping decay curve. Table 2 presents details of the four earthquake records that were chosen to generate the five acceleration histories used in this study, with Table 3 summarising the sequence of the records.

Generation of the five acceleration histories reported in Table 3 was conducted with the objective of further expanding the suite of loading histories to be used in the structural testing programme reported by Ingham et al. (2001). Notably, laboratory loading histories used worldwide have the general characteristics of causing escalating damage until failure occurs, and are 'artificial' as they do not closely reflect recorded earthquake timehistory response. Similarly, the individual earthquake records used in each of the histories of Table 3 were scaled such that they provided artificial records significantly different from standard laboratory routines, while ensuring failure of the laboratory subassemblage. It is not implied that the acceleration histories reported in Table 3 reflect the nature of shaking that the building may be subjected to.

Table 3 reveals that an additional earthquake record was applied for the final three acceleration histories. The inclusion of another damaging earthquake record was to ensure that the test subassemblage would fail during application of the acceleration sequence.

An indicative acceleration history is shown in Fig. 5, and the five resultant load histories at the critical beam plastic hinge are reported in Ingham et al. (2001). The predicted force-displacement response of the corresponding test assemblages is shown in Fig. 6, and may be compared with the experimentally recorded data reported in Fig. 21 of the companion paper.

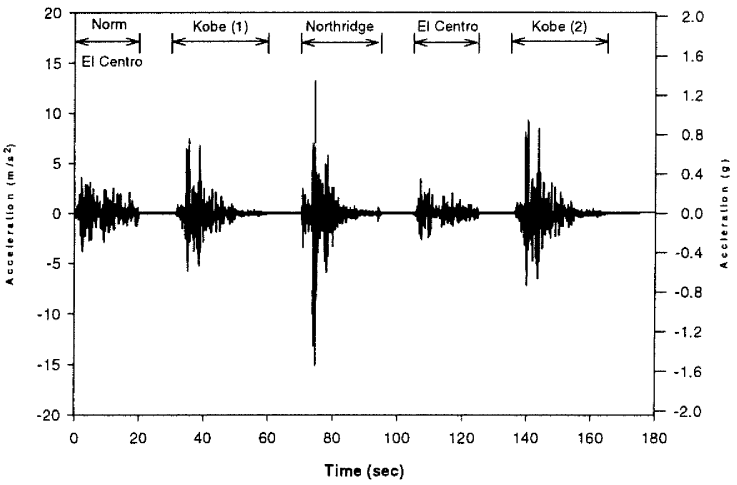

Figure 5: Acceleration History C.

\section{PERFORMANCE DESCRIPTORS}

As defined in this study, performance descriptors attempt to quantify the damage sustained in concrete structures due to seismic loading. Performance descriptors aid retrofit decisions, disaster planning, and post-earthquake assessment of affected structures.

\subsection{Displacement, ductility and drift}

The most traditional and simple performance descriptor is displacement ductility. Displacement ductility is defined as the ratio of maximum displacement achieved to the yield displacement:

$$
\mu=\frac{\delta_{\max }}{\delta_{y}} .
$$

There are a number of methods available that establish the yield displacement of a reinforced concrete member. This investigation applied the elasto-plastic approximation procedure shown in Fig. 7.

Because of the dependence on definition of the yield displacement, the use of ductility as a performance descriptor is often less suitable than describing response in terms of drift. Typically drift is expressed as the ratio of the maximum displacement to the inter-storey height, as a percentage:

$$
\text { drift }=\frac{\delta_{\max }}{h} \times 100 \% .
$$

\subsection{Visible Damage}

Visible damage is an obvious parameter used to access structural response. This typically involves consideration of the width, orientation and prevalence of cracks, and of crushing and spalling of concrete. Crack widths indicate the extent of plastic reinforcement straining, and crack orientation illustrates the force paths and modes of deformation within the structural element. In severe cases, crushing and spalling of concrete from either the cover or the core, and rupture of the transverse or longitudinally reinforcement, are indicators of failure. 


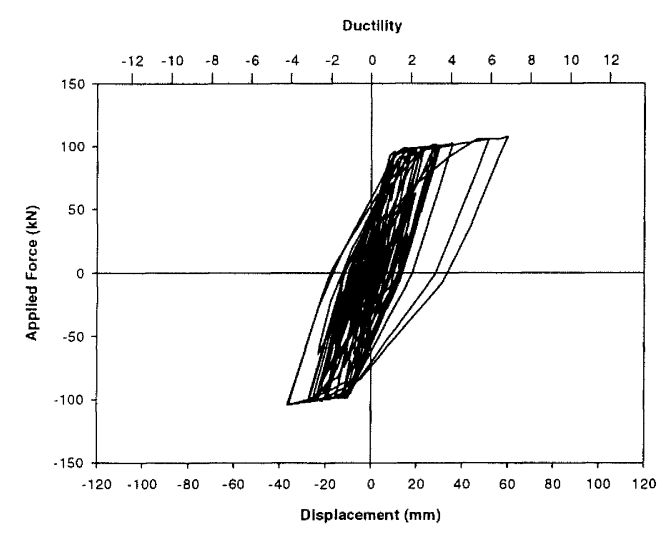

Figure 6(a): Predicted Force-Displacement Response (Acceleration History A).

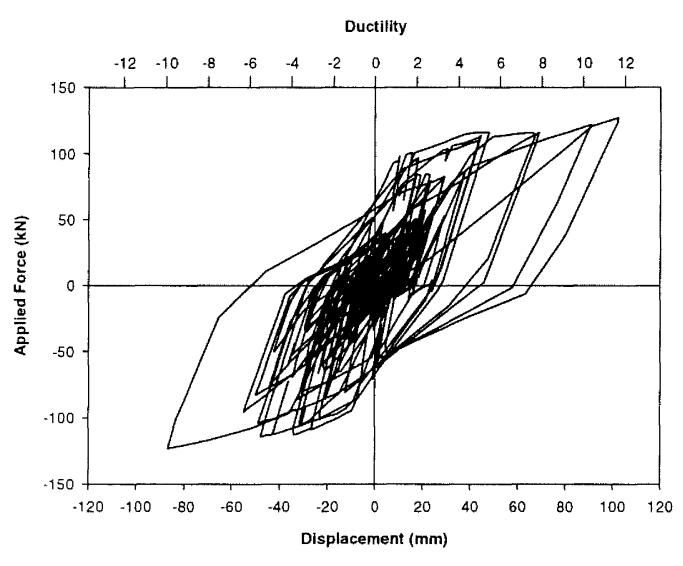

Figure 6(c): Predicted Force-Displacement Response (Acceleration History C).

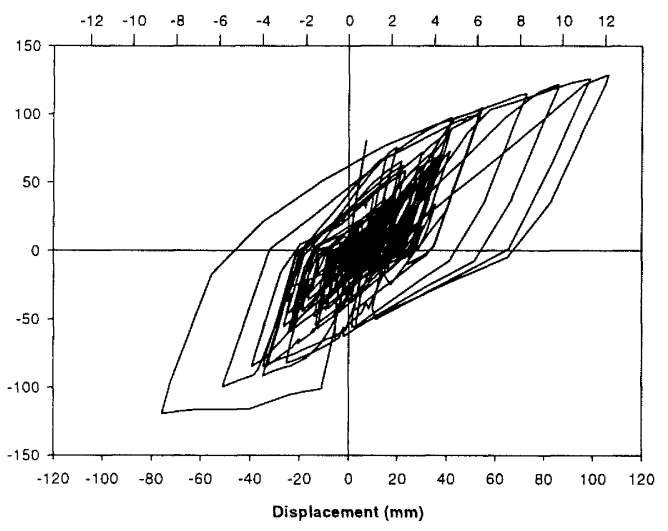

Figure 6(e): Predicted Force-Displacement Response (Acceleration History E).

Another parameter capturing the cumulate effect of damage is growth of the plastic hinge length. This total elongation is a summation of the width of individual cracks that may form from positive and negative bending, or forms due to shear. This parameter has received increased attention recently due to concerns about unseating of floors as the beams of seismically loaded frames elongate during an earthquake.

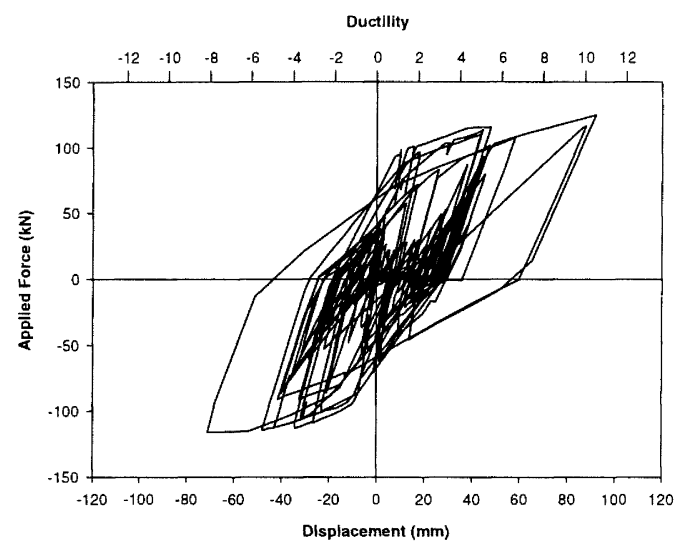

Figure 6(b): Predicted Force-Displacement Response (Acceleration History B).

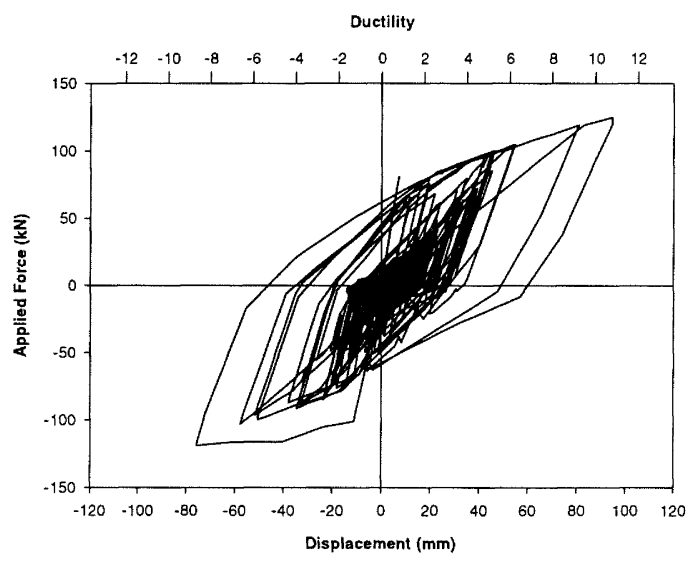

Figure $6(d)$ : Predicted Force-Displacement Response (Acceleration History D).

\subsection{Damage Indices}

The most common performance descriptors are those that are ductility based. However such descriptors fail to consider the cumulative effect of repeated cycles. This led researchers to propose damage indices that accounted for cumulative loading.

\subsubsection{Cosenza et al. Index}

A structural damage index provides a measure of the demand on a structural element. The damage index has minimum and maximum values relating to undamaged and failure conditions respectively. Between these two extremes, the damage index is related to the damage parameter by a damage function. Powell and Allahabadi (1988) proposed the following general damage function:

$$
\mathrm{D}=\left(\frac{\delta-\delta_{\mathrm{y}}}{\delta_{\mathrm{u}}-\delta_{\mathrm{y}}}\right)^{\mathrm{m}},
$$

where $\delta$ was defined as the damage parameter at a certain level, $\delta_{y}$ was defined as the minimum value relating to an undamaged state, and $\delta_{u}$ was defined as the ultimate value relating to failure. The variable $\mathrm{m}$ allowed more complex relationships between the damage parameter and the damage index to be assumed. 


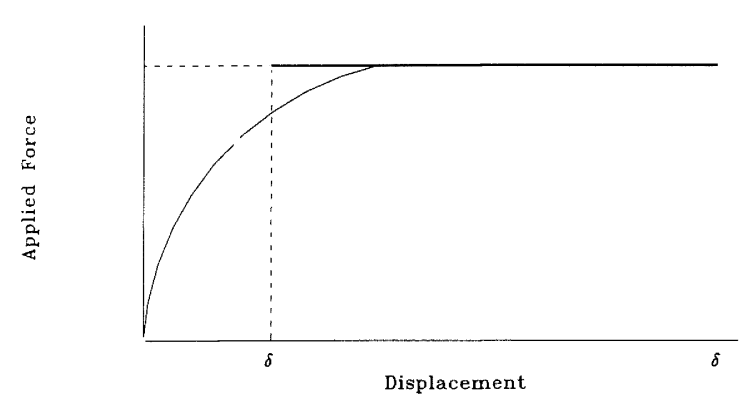

Figure 7: Elasto-Plastic Approximation.

Cosenza et al. (1993) defined the displacement ductility value expressed in Eq. 1 as a measure of the damage parameter defined in Eq. 3. This was incorporated by setting $\mathrm{m}$ equal to 1.0 and defining the ultimate value as the ductility obtained under monotonic testing to give the following expression:

$$
D=\left(\frac{\left(\delta / \delta_{y}\right)-\left(\delta_{y} / \delta_{y}\right)}{\left(\delta_{u} / \delta_{y}\right)-\left(\delta_{y} / \delta_{y}\right)}\right)^{1.0}
$$

which was simplified to give

$$
\mathrm{D}=\frac{\mu-1}{\mu_{\mathrm{u}}-1} .
$$

A value less than zero indicates that yielding has not occurred and hence, the member is undamaged. In contrast a value equal to 1.0 represents failure of the member.

\subsubsection{Roufaiel and Meyer Index}

The previous damage index did not include the effects of repeated cycling. The ability of a structure to withstand an earthquake depends on the degradation of strength and stiffness suffered during previous earthquakes. Therefore, Roufaiel and Meyer (1987) proposed a model that was based on the reduction in secant stiffness. Although cumulative damage was not accounted for, the model was an improvement on displacement ductility as it took some account of the stiffness and strength degradation that occurs under earthquake loading.

Roufaiel and Meyer proposed that the maximum modified flexural damage ratio (MFDR) from positive or negative loading should be established as an indicator of member damage. The modified flexural damage ratio was defined as:

Table 4: Park and Ang Damage Classification Levels.

\begin{tabular}{|c|c|}
\hline$D<0.1$ & No damage or localised cracking \\
\hline $0.1 \leq D<0.25$ & Minor damage \\
\hline $0.25 \leq D<0.4$ & Moderate damage \\
\hline $0.4 \leq D<1.0$ & Severe damage \\
\hline$D \geq 1.0$ & Collapse \\
\hline
\end{tabular}

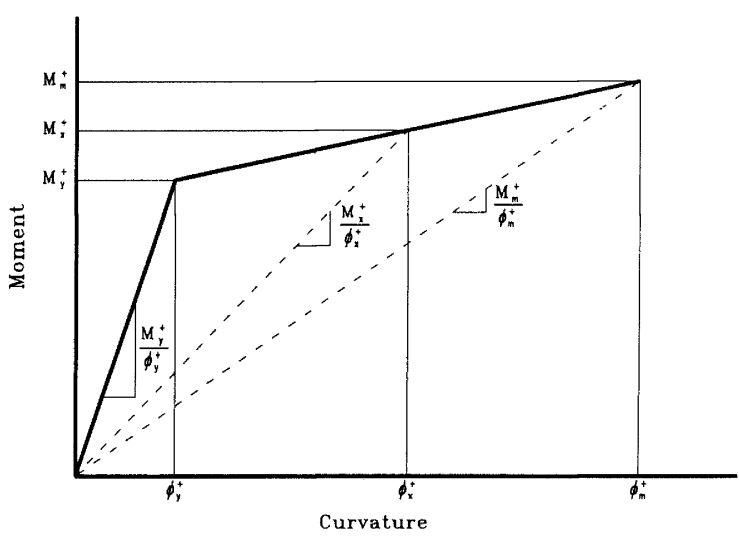

Figure 8: Definition of Modified Flexural Damage Ratio (Roufaiel and Meyer 1987).

$$
\operatorname{MFDR}=\frac{\phi_{\max } / \mathrm{M}_{\max }-\phi_{\mathrm{y}} / \mathrm{M}_{\mathrm{y}}}{\phi_{\mathrm{u}} / \mathrm{M}_{\mathrm{u}}-\phi_{\mathrm{y}} / \mathrm{M}_{\mathrm{y}}}
$$

and is illustrated in Fig. 8.

As with the damage index proposed by Cosenza et al., the member is undamaged when the MFDR is less than or equal to zero, and has failed when the MFDR is equal to 1.0 .

\subsubsection{Park and Ang Index}

One of the more commonly applied damage indices is that proposed by Park and Ang (1985). Damage is defined as a linear combination caused by deformation and cyclic loading, and expressed mathematically as:

$$
\mathrm{D}=\frac{\delta_{\operatorname{mix}}}{\delta_{\mathrm{u}}}+\frac{\beta}{\mathrm{F}_{\mathrm{y}} \delta_{\mathrm{u}}} \int \mathrm{dE} .
$$

In Eq. $7 \delta_{\max }$ is the maximum deformation during an earthquake or test and $\delta_{\mathrm{u}}$ is the ultimate deformation obtained from monotonic loading. $F_{y}$ is the force associated with the calculated yield moment and $\mathrm{dE}$ is defined as the incremental dissipated hysteresis energy. Lastly, $\beta$ is a non-dimensional parameter representing the effect of cyclic loading and is defined in Eq. 8:

$$
\beta=\left(0.447+0.073 \frac{\ell}{d}+0.24 n_{0}+0.314 \rho_{1}\right) \times 0.7^{\rho_{s}}
$$

Several terms represented in Eq. 8 have lower bound values. These are the shear span ratio, $l / d$, which has a minimum value equal to 1.7 , the normalised axial stress, $\mathrm{n}_{0}$, which has a minimum value equal to 0.2 , and the longitudinal steel ratio as a percentage, $\rho_{t}$, which had a minimum value of $0.75 \%$. Park and Ang suggested the classification levels in Table 4 based on the observed damage of nine reinforced concrete buildings from the 1971 San Fernando earthquake.

\subsubsection{Banon and Veneziano Index}

Banon and Veneziano (1982) proposed another damage index based on a combination of ductility and dissipated 
energy. They developed a probabilistic damage index that gave the probability of survival at a certain time as a function of the flexural damage ratio and the dissipated energy up to that time.

The flexural damage ratio was defined as the ratio of stiffness at the yield point to the secant stiffness at failure. This was also the ratio of the maximum displacement to the yield displacement:

$$
\mathrm{d}_{1}=\frac{\delta_{\max }}{\delta_{\mathrm{y}}}=\mu
$$

The second damage parameter was defined as the plastic dissipated energy normalised with respect to the absorbed energy at the elastic limit in the first quadrant:

$$
\mathrm{d}_{2}=\frac{2 \mathrm{E}_{\mathrm{h}}}{\mathrm{F}_{\mathrm{y}} \delta_{\mathrm{y}}}
$$

Eqs. 9 and 10 were then modified as demonstrated in Eqs. 11 and 12:

$$
\begin{gathered}
\mathrm{d}_{1}^{*}=\mathrm{d}_{1}-1 \\
\text { and } \mathrm{d}_{2}^{*}=1.1 \mathrm{~d}_{2}^{0.38} \text {. }
\end{gathered}
$$

The modified damage parameters where combined to give a damage index function and normalised by the value obtained under monotonic loading to give:

$$
\mathrm{D}=\frac{\sqrt{\left(\frac{\mathrm{x}_{\max }}{\mathrm{x}_{\mathrm{y}}}-1\right)^{2}+\left(1.1\left(\frac{2 \mathrm{E}_{\mathrm{h}}}{\mathrm{F}_{\mathrm{x}} \mathrm{x}_{\mathrm{y}}}\right)^{0.38}\right)^{2}}}{\text { MonotonicValue }},
$$

which is the final form of the damage index.

\subsubsection{Bracci et al. Index}

Bracci et al. (1989) proposed a damage index based on the relation of demand and capacity. Damage demand consisted of strength loss and deformation related damage. The damage potential, $D_{p}$, the strength damage, $D_{s}$, and the deformation damage, $D_{d}$ were defined graphically and combined. An origin-centred bilinear relationship was assumed, and the initial and postyielding stiffness were taken to be the same in both directions. This led to the following damage index equation:

$$
\begin{aligned}
D & =\frac{\Delta M\left(\phi_{u}-\phi_{y}\right)+\left(M_{y}-\Delta M\right)\left(\phi_{\max }-\phi_{y}\right)}{M_{y}\left(\phi_{u}-\phi_{y}\right)} \\
& =D_{1}+D_{2}-D_{1} D_{2}
\end{aligned}
$$

in which

$$
\mathrm{D}_{1}=\frac{\phi_{\max }-\phi_{\mathrm{u}}}{\phi_{\mathrm{u}}-\phi_{\mathrm{y}}}
$$

and

$$
\mathrm{D}_{2}=\frac{\Delta \mathrm{M}}{\mathrm{M}_{\mathrm{y}}}
$$

In Eq. $15, \phi_{\max }$ is defined as the curvature at the maximum recorded displacement, $\phi_{y}$ is defined as the curvature at the force corresponding to the yield moment, and $\phi_{\mathrm{u}}$ is the curvature at the ultimate displacement established from monotonic loading. In Eq. 16, $\Delta \mathrm{M}$ is found to be dependent on the dissipated energy, the yield curvature, and a strength deterioration factor as detailed in Eq. 17:

$$
\Delta \mathrm{M}=\frac{\mathrm{S}_{\mathrm{sd}} \int \mathrm{dE}}{\phi_{\mathrm{y}}} .
$$

The strength deterioration factor in Eq. 17 is dependent on the axial load, the longitudinal and transverse confinement ratios, and the material strengths of the component. A regression analysis on experimental results from 21 elements with the influencing parameters previously mentioned was conducted to give the following expression for the strength deterioration factor:

$$
S_{s d}=0.00857\left(1+12 \frac{P_{c}}{A_{g} f_{c}^{\prime}}\right)\left(1-0.5 \frac{\rho_{s} f_{y l}}{0.85 f_{c}^{\prime}}\right)\left(1-\frac{\rho_{t} f_{y}}{0.85 f_{c}^{\prime}}\right)
$$

Bracci et al. suggested four classification states based on experimental behaviour, as shown in Table 5 .

Bracci et al. compared these classification levels with those proposed by Park and Ang, and concluded that although collapse occurred in both models when the damage index was equal to 1.0 , the irreparable state varied between the two models. The above model classified a structure as irreparable once the damage index is greater than 0.66 whereas the Park and Ang model classified a structure as irreparable once the damage index is greater than 0.4 . The difference was due to damage in the model proposed by Bracci et al. being more linearly distributed between 0.0 and 1.0 than the model proposed by Park and Ang, where considerable damage was evident at small damage index values.

\section{ASSESSMENT OF PERFORMANCE DESCRIPTORS}

In this section the adequacy of candidate performance descriptors is assessed with respect to the experimental data reported in Ingham et al. (2001).

Table 5: Bracci et al. Damage Classification Levels.

\begin{tabular}{|c|c|}
\hline$D \leq 0.33$ & Serviceable State \\
\hline $0.33<D \leq 0.66$ & Repairable State \\
\hline $0.66<D \leq 1.0$ & Irrepairable State \\
\hline$D>1.0$ & Collapse State \\
\hline
\end{tabular}




\section{$5.1 \quad$ Force-displacement response}

The force-displacement response derived from the twelve beam tests revealed large discrepancies between the measured ultimate displacement, with the ultimate displacement derived from monotonic loading being far in excess of that derived from any of the bi-directional cyclic procedures. This is consistent with the findings of Tomazevic et al. (1996), where it was established that larger ultimate displacements were recorded using monotonic loading than when cyclic loading of any type was applied. The measured ultimate displacement derived using the four laboratory loading histories also varied, indicating that displacement, ductility, and drift were not satisfactory performance indicators independent of loading history.

Given that degradation at the conclusion of acceleration histories B, C, and E were similar (see Fig. 21 of Ingham et al. 2001), it is evident that variations in the applied displacement sequence did not cause significant discrepancies in the overall response of these test units. This is consistent with the conclusions made by Hwang and Scribner (1984). However, this is in contrast to earlier comments made about the significance of different laboratory loading procedures, consequently supporting the notion that response is comparatively independent of loading histories as long as the total number and magnitude of cycles is preserved. This conclusion supports consideration of the total energy content of the loading history.

Results indicated that the post-yield force-displacement response from monotonic loading formed an envelope to response from cyclic tests. Results also indicated that the amount of pinching and the reloading stiffness were not reliable indicators of the amount of degradation that had occurred. Instead these parameters need to be considered in conjunction with the composition of the total displacement and the energy dissipation characteristics of the displacement components before comparisons can be made.

\subsection{Energy Dissipation}

Results indicated that the energy dissipation characteristics were strongly load history dependent. This was consistent with the conclusions reached by Kunnath et al. (1997). Significant differences were measured between the energy dissipated during testing using the four laboratory loading histories, with little consistency in either the cumulative dissipated energy or the measured cumulative ductility.

Generally, large amounts of energy were dissipated at later stages of testing when using laboratory loading procedures, once ductility levels were increased. This behaviour was previously noted by Lefas and Kotsovos (1990).

Energy dissipation characteristics from testing using the five acceleration histories demonstrated that the dissipated energy from acceleration histories B-E were similar. This was consistent with the conclusions stated by Hwang and Scribner (1984). This and the previous comments regarding load history dependence imply that energy dissipation parameters are not sufficiently independent of the applied loading history to be used as performance descriptors.

\subsection{Visible damage}

Measured data considering crack widths and beam elongation indicated no discernable correlation with the applied loading history. While these parameters are clearly indicators of damage, they are discounted as being satisfactory performance descriptors permitting correlation between loading histories.

Similar reinforcement strain data from monotonic and unidirectional loading were recorded for loading up to and including ductility 8 . The measured data did not endorse the conclusion by Kinugasa and Nomura that failure occurred within a narrow range of peak reinforcement strain values. Thus, the magnitude of longitudinal reinforcement strains gave no indication of the point of failure and hence, cannot be used as performance descriptors.

\subsection{Damage Indices}

Damage indices were calculated from the experimental data obtained from the twelve tests. Five different indices were calculated to enable comparison: Cosenza et al., Roufaiel and Meyer, Park and Ang, Banon and Veneziano, and Bracci et al.

Table 6: Comparison of Predicted and Actual Damage Indices (At Conclusion of Test).

\begin{tabular}{|c|c|c|c|}
\hline Acceleration History & Damage Index & Predicted & Actual \\
\hline \multirow[t]{5}{*}{ A } & Roufaiel \& Meyer & 0.29 & 0.29 \\
\hline & Park \& Ang & 0.54 & 0.43 \\
\hline & Cosenza et al. & 0.26 & 0.26 \\
\hline & Banon and Veneziano & 0.42 & 0.38 \\
\hline & Bracci et al. & 0.54 & 0.40 \\
\hline \multirow[t]{5}{*}{ B } & Roufaiel \& Meyer & 0.45 & 0.47 \\
\hline & Park \& Ang & 0.75 & 0.76 \\
\hline & Cosenza et al. & 0.42 & 0.42 \\
\hline & Banon and Veneziano & 0.55 & 0.55 \\
\hline & Bracci et al. & 0.70 & 0.69 \\
\hline \multirow[t]{5}{*}{$\mathrm{C}$} & Roufaiel \& Meyer & 0.50 & 0.56 \\
\hline & Park \& Ang & 0.96 & 0.89 \\
\hline & Cosenza et al. & 0.49 & 0.49 \\
\hline & Banon and Veneziano & 0.64 & 0.62 \\
\hline & Bracci et al. & 0.84 & 0.79 \\
\hline \multirow[t]{5}{*}{ D } & Roufaiel \& Meyer & 0.47 & 0.78 \\
\hline & Park \& Ang & 0.89 & 0.81 \\
\hline & Cosenza et al. & 0.45 & 0.45 \\
\hline & Banon and Veneziano & 0.60 & 0.58 \\
\hline & Bracci et al. & 0.81 & 0.74 \\
\hline \multirow[t]{5}{*}{$E$} & Roufaiel \& Meyer & 0.52 & 0.54 \\
\hline & Park \& Ang & 0.92 & 0.91 \\
\hline & Cosenza et al. & 0.51 & 0.51 \\
\hline & Banon and Veneziano & 0.64 & 0.64 \\
\hline & Bracci et al. & 0.81 & 0.80 \\
\hline
\end{tabular}




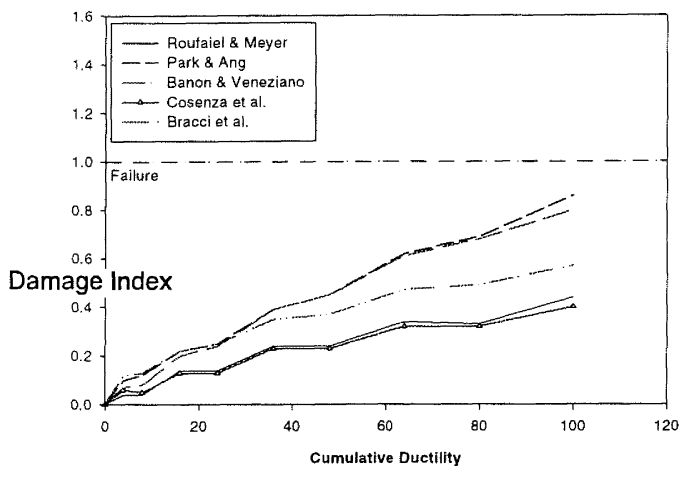

Figure 9(a): Damage Indices (New Zealand Loading History).

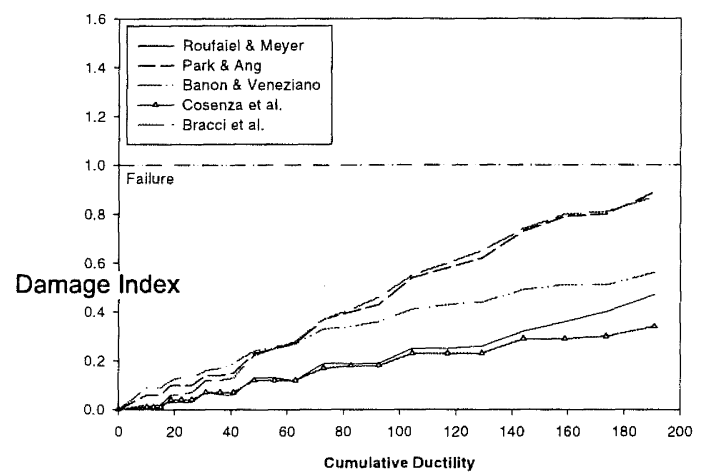

Figure 9(c): Damage Indices (PRESSS Loading History).

\subsubsection{Comparison of Predicted Damage Indices with Actual Damage Indices}

Prediction of the maximum values for the respective damage indices was based on the force-displacement response obtained from the Ruaumoko analyses. Table 6 compares the predicted and actual maximum value for each damage index from each acceleration history. Comparison of the values in Table 6 reveals excellent agreement between the predicted damage indices and the actual damage indices. However, this excellent agreement occurred partly by default because the displacement sequence applied in the laboratory was taken from the displacement-time history derived from analysis.

Of the three indices based on a combination of damage due to deformation and damage due to dissipated energy, the Banon and Veneziano index gave the best correlation between the predicted and actual values. The Bracci et al. index and the Park and Ang index generally overpredicted the amount of damage that occurred. This was due to the hysteresis model failing to accurately account for pinching in the hysteresis loops and for strength degradation near conclusion of the test.

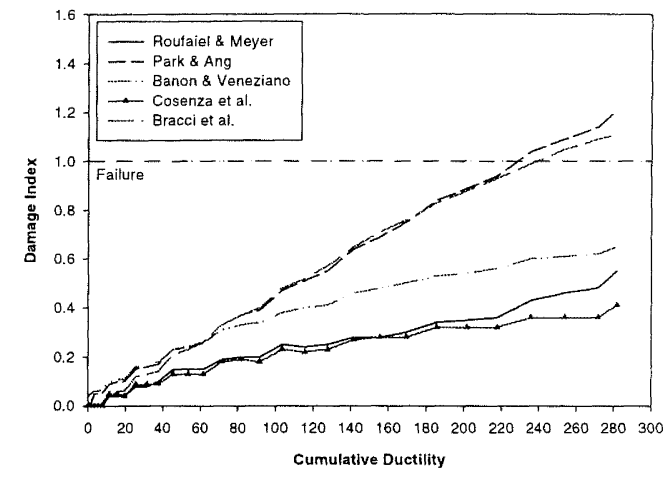

Figure 9(b): Damage Indices (Berkeley Loading History).

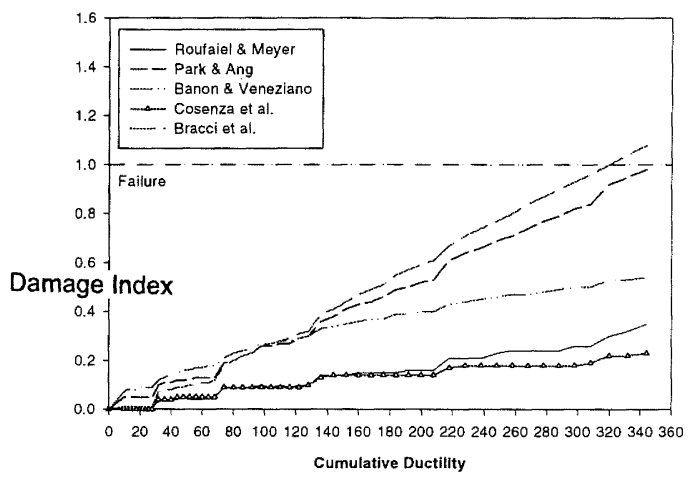

Figure 9(d): Damage Indices (Public Works Research Institute).

\subsubsection{Comparison of Actual Damage Indices with Observed Damage}

Five damage levels were defined in this study based on a review of previously published damage criteria (Applied Technology Council 1989; Williams and Sexsmith 1995; Williams et al. 1997). Table 7 categorises the observed damage into the five damage levels. In Liddell (2000) thorough assessment is given of the criteria given in Table 7, and of correlation with the two indices of Tables 4 and 5. Detailed discussion is provided here only for the Park and Ang index and the Bracci index as these were the only indices to define intermediate damage values.

Fig. 9(a) displays the damage indices calculated using the New Zealand loading history. Of the five damage

Table 7: Criteria for Damage Levels.

\begin{tabular}{|c|l|}
\hline Damage State & \multicolumn{1}{|c|}{ Observed Behaviour } \\
\hline No Damage & $\begin{array}{l}\text { Small amounts of flexural and shear cracking may be evident. } \\
\text { However, the widths of these cracks will be less than 0.5mm. }\end{array}$ \\
\hline Minor Damage & $\begin{array}{l}\text { The widths of any flexural or shear cracks will be less than } 1.0 \mathrm{~mm} \\
\text { No concrete spalling is evident. }\end{array}$ \\
\hline Moderate Damage & $\begin{array}{l}\text { Damage occurring after this level is generally defined as being } \\
\text { irreparable. Flexural or shear cracks will be less than } 3.0 \mathrm{~mm} . \\
\text { Limited concrete spalling will occur. However, this will not result in } \\
\text { exposure of transverse or longitudinal reinforcement. }\end{array}$ \\
\hline Severe Damage & $\begin{array}{l}\text { Further crushing of concrete in the plastic hinge zone will occur. } \\
\text { Spalling of cover concrete such that longitudinal and transverse } \\
\text { reinforcement is visible will occur. }\end{array}$ \\
\hline Collapse & $\begin{array}{l}\text { Buckling of the longitudinal reinforcement will be evident at this } \\
\text { damage level. Rupture of longitudinal reinforcement may occur. }\end{array}$ \\
\hline
\end{tabular}




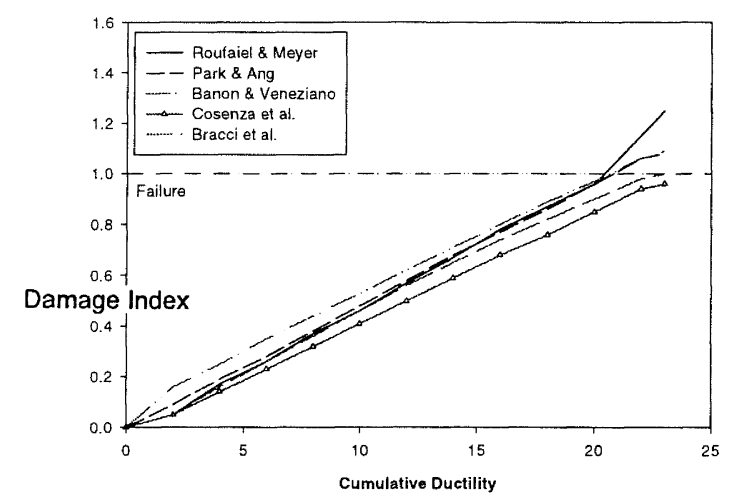

Figure 10(a): Damage Indices (Monotonic Loading).

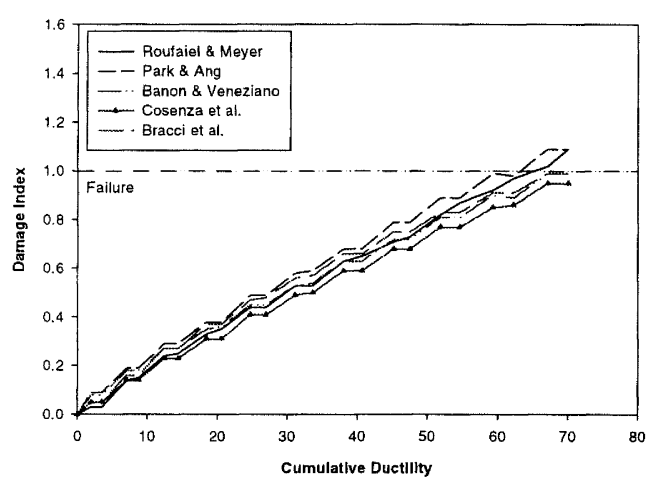

\section{Figure 10(c): Damage Indices (Unidirectional Loading).}

indices, the Park and Ang index and the Bracci index were closest to correctly defining failure. The five damage indices increase in a stepwise manner, where the plateau corresponds to the second cycle at each ductility level. This was consistent with observed behaviour from testing, where little additional damage was observed during the repeat cycles. The Bracci index exhibited a level of agreement similar to the Park and Ang index, with both indices being in satisfactory agreement with observed response.

Fig. 9(b) presents the damage indices calculated using the Berkeley loading history. The values returned by the Park and Ang index were comparable with the observed damage when grouped into the five categories of Table 7 . The calculated Bracci index revealed similar results to the Park and Ang index. Observed damage was more severe than that defined by the Bracci index at the minor and moderate damage levels. However, the observed damage was consistent with the calculated Bracci index once the severe and collapse damage levels were reached.

Fig. 9(c) details the damage indices calculated from the PRESSS loading history. Comparison of the calculated Park and Ang index and the Bracci index with observed damage revealed poor correlation, with damage being more severe in the minor and moderate damage levels. However, in contrast to the Park and Ang index, the Bracci index also showed poor correlation once the damage reached the severe stage.

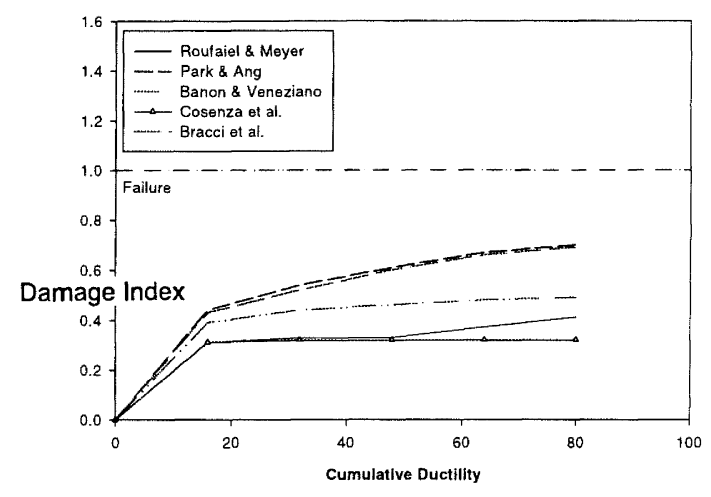

Figure 10(b): Damage Indices (Bi-directional Cycling at Ductility 8).

Fig. 9(d) presents the damage indices calculated using the loading history from the Public Works Research Institute. Failure of the test subassemblage was defined accurately using the Park and Ang index, with the strength of the test subassemblage dropping below $80 \%$ of the maximum-recorded strength at an identical ductility to the designated failure ductility from the damage index. The Bracci index also gave very close correlation.

Fig. 10(a) illustrates the damage indices calculated from testing where monotonic loading was applied. The comparison characteristics of the Park and Ang index and the Bracci index corresponded closely to observed damage levels, except that crack widths were wider than the allowable limits.

Fig. 10(b) details the damage indices calculated when bidirectional cycling at ductility 8 was applied and reveals that none of the five damage indices defined failure of the beam as having occurred. This was because the five damage indices were not based on the principles of fatigue loading. This was supported in a study by Kunnath et al. (1997) on the development of a fatiguebased cumulative damage model, where it was concluded that indices such as the Park and Ang index and the Roufaiel and Meyer index were unable to accurately predict the final damage state of the test subassemblage.

Fig. 10(b) illustrates that the indices that accounted for the amount of energy dissipated during the test gave the best indication of the amount of damage incurred. Fatigue models proposed by Kunnath et al. and Mander (1998) were applied to this test but returned poor correlation to the observed damage. This was not unexpected as these models were calibrated with respect to concrete columns instead of the formation of beam plastic hinges. The values returned by the Park and Ang index predicted that severe damage had occurred after the first cycle. This was consistent with the observed damage from the test where crushing of concrete and spalling of concrete were both apparent. Comparison between predicted damage using the calculated Bracci index and the observed damage revealed poor correlation.

Fig. 10(c) displays the damage indices calculated for testing applying unidirectional loading. This figure 


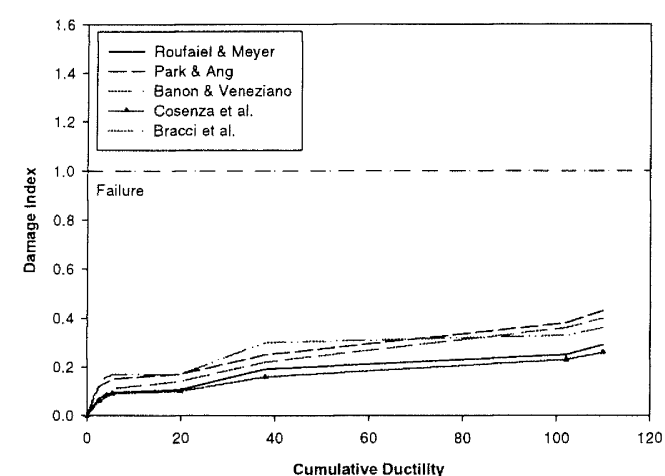

Figure 11(a): Damage Indices (Acceleration History A).

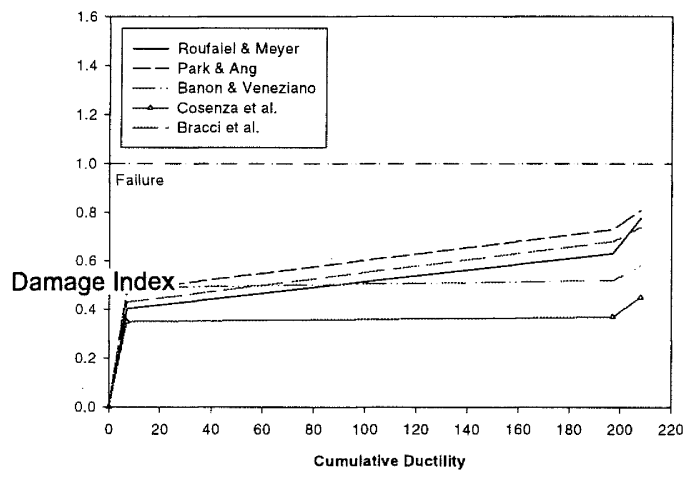

Figure 11(c): Damage Indices (Acceleration History C).

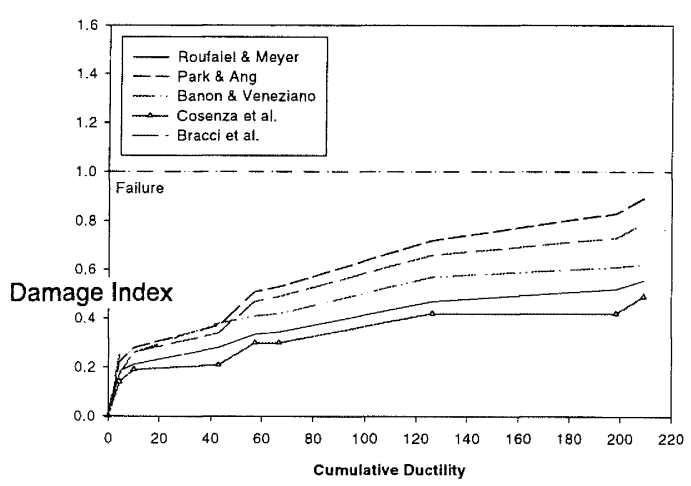

Figure 11(e): Damage Indices (Acceleration History $E$ ).

reveals that all five damage indices predicted failure. However, this was expected because the ultimate ductility reached in this test was comparable to the ultimate ductility reached when applying monotonic loading. All five damage indices increased in a stepwise manner with the plateau corresponding to the second cycle at each ductility level.

Fig. 11(a) details the damage indices calculated from acceleration history A, which did not fail when tested in the laboratory. This figure reveals that all five damage indices specified that failure would not occur. Of the

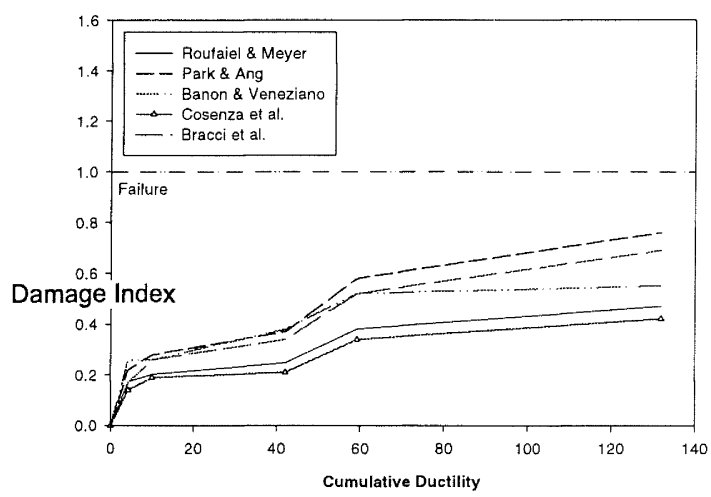

Figure 11(b): Damage Indices (Acceleration History $\mathrm{B}$ ).

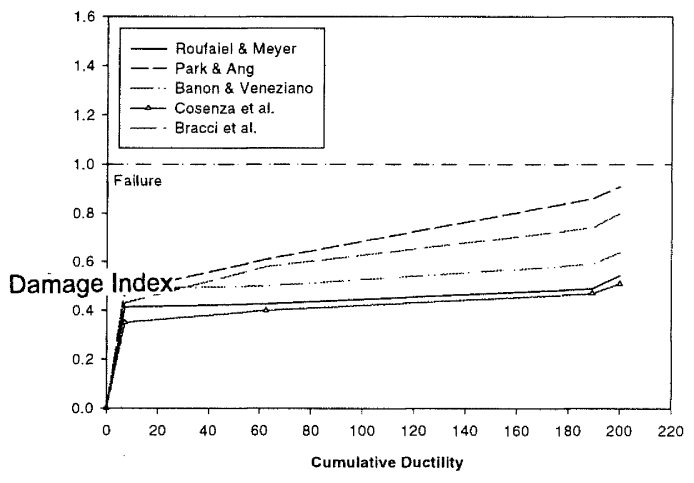

Figure 11(d): Damage Indices (Acceleration History D).

damage indices that defined intermediate values, the Park and Ang index classified the damage as severe whereas the Bracci index classified the damage as moderate. The values returned by the Park and Ang index revealed poor correlation between the calculated damage index and the observed damage. Spalling was not seen at any stage of the test even though the damage index predicted that severe damage would occur. As with other tests, crack widths were greater than allowed for their respective damage states. Comparison of the calculated Bracci index and the observed damage revealed slightly better correlation than the Park and Ang index although the measured crack widths were wider than the limits detailed in Table 7.

Fig. 11(b) presents the damage indices calculated using acceleration history B. Again, none of the five indices predicted the collapse damage level, although the Park and Ang index and the Bracci index both specified that severe damage occurred.

The Park and Ang index defined the damage incurred during application of the Normalised El Centro record as moderate damage. However, after loading to this stage, spalling of cover concrete meant that a transverse stirrup was visible. This behaviour corresponded to severe damage as defined in Table 7 . Crack widths were also in excess of the allowable limits. However, damage observed near conclusion of the test was consistent with 


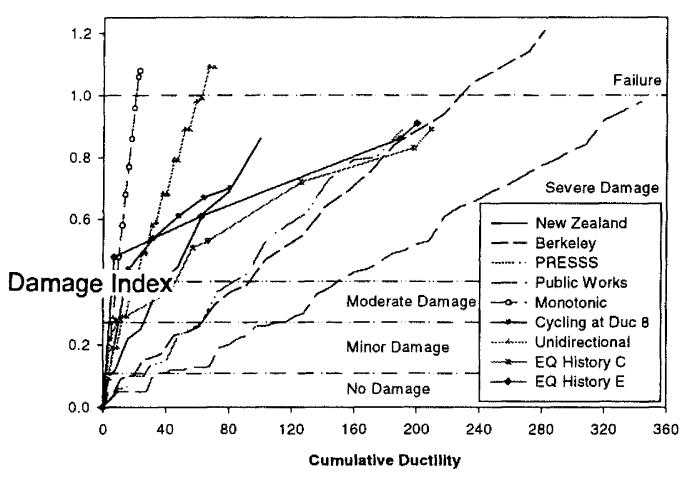

Figure 12: Comparison of Park and Ang Damage Index for Tests where Failure Occurred.

the damage descriptions listed in Table 7. Severe damage was said to have occurred during application of the Northridge earthquake record. Crushing of concrete and continued spalling were observed during that record.

The Bracci index revealed similar results to the Park and Ang index. Again damage was more severe in the minor and moderate damage levels. However, observed damage was consistent with the calculated index once the severe and failure damage levels were reached.

Fig. 11(c) illustrates the damage indices calculated from testing using acceleration history $\mathrm{C}$. Of the five damage indices, the Park and Ang index was the only index that was close to specifying failure. The Bracci index classified damage as severe.

The values returned by the Park and Ang index were comparable with the observed damage grouped into the five damage levels for the entire test. The damage incurred during the Normalised El Centro record was defined as moderate damage with minor spalling of cover concrete being observed. This is consistent with the behaviour described in Table 7 as moderate damage. Severe damage was defined as occurring during the first Kobe record. Transverse and longitudinal reinforcement was visible and crushing of concrete was also apparent. Again this is consistent with the behaviour described in Table 7. Significant spalling of cover concrete, such that approximately $300 \mathrm{~mm}$ of longitudinal reinforcement was visible, occurred during the second Kobe record. This reflected the large amount of degradation that had taken place by that stage of the test. Comparison of the calculated Bracci index and the observed damage revealed similar results to the Park and Ang index, although crack widths did not correlate to the limits described in Table 7.

Fig. 11(d) details the damage indices calculated from testing using acceleration history $\mathrm{D}$, with none of the five damage indices predicting collapse. However, this was largely due to premature rupture of a longitudinal bar. This led to significant strength reduction and a corresponding loss of energy absorbed, which reduced the values calculated by the Park and Ang index and the Bracci index.
The Park and Ang index was consistent with the observed damage prior to rupture of the longitudinal bar. Severe damage was defined as occurring during application of the Northridge earthquake record, with spalling of cover concrete and exposure of transverse reinforcement occurring during application of this record. The measured crack widths were also consistent with the limits described in Table 7.

The Bracci index did not provide an accurate representation of the physical damage for this test. Damage incurred during the Northridge record was defined as moderate damage when, as previously mentioned, the physical damage was consistent with the characteristics of severe damage.

Fig. 11(e) presents the damage indices calculated from experimental data recorded during testing using acceleration history E. Again the Park and Ang index was the only index that specified that failure would occur, with the Bracci index classifying damage as belonging to the severe damage level.

The Park and Ang index was consistent with the observed damage for the duration of the test. Severe damage was defined as occurring during application of the Northridge earthquake, with crushing and spalling of concrete being evident. The measured crack widths were also consistent with the limits listed in Table 7. Spalling continued to occur throughout this test and significant degradation had occurred by conclusion of this acceleration history. Poor correlation was obtained between the calculated Bracci index and the observed damage. Damage incurred during the Northridge record was classified as moderate damage, which clearly was not the case.

\subsubsection{Relevance of Damage Indices}

Of the five damage indices, the Park and Ang index and the Bracci index were the only indices that repeatedly returned values at the end of the test that were comparable with the observed damage. This indicates that damage indices that are a combination of damage due to deformation and cumulative cycling return the best correlation to the observed damage. Of the two, the Park and Ang index generally provided the best correlation between the calculated values and the observed damage.

Crushing and spalling of concrete were usually well predicted by the Park and Ang index. In contrast, the measured crack widths were typically wider than predicted. Damage at the severe damage level was dominated by the spalling of concrete and the exposure and buckling of longitudinal reinforcement, with crack widths difficult to establish once severe damage was reached.

Although the Park and Ang index returned values that were comparable to the observed damage at the end of the test, minor improvements could be made. On several occasions the maximum value for the index was in the range of 0.8 to 0.9 . This was slightly less than the value corresponding to collapse as listed in Table 4 . The value 
Table 8: Recommendations for Damage Level criteria.

\begin{tabular}{|c|l|}
\hline Damage State & \multicolumn{1}{|c|}{ Observed Behaviour } \\
\hline No Damage & $\begin{array}{l}\text { Small amounts of flexural and shear cracking may be evident. } \\
\text { However, the widths of these cracks will be less than 0.5mm. }\end{array}$ \\
\hline Minor Damage & $\begin{array}{l}\text { Widespread cracking within a distance } 2 \mathrm{~h} \text { from the face of the beam- } \\
\text { column joint will occur. The widths of any flexural or shear cracks } \\
\text { will be less than 1.0mm. No concrete spalling is evident. }\end{array}$ \\
\hline Moderate Damage & $\begin{array}{l}\text { Damage occurring after this level is generally defined as being } \\
\text { irreparable. Flexural or shear cracks will be less than 3.0mm. } \\
\text { Limited concrete spalling will occur. However, this will not result in } \\
\text { exposure of transverse or longitudinal reinforcement }\end{array}$ \\
\hline Severe Damage & $\begin{array}{l}\text { Little additional cracking will form between this damage level and the } \\
\text { moderate damage level. Flexural and shear cracks in the plastic } \\
\text { hinge zone will continue to widen with crack widths reaching 10mm. } \\
\text { Further crushing of concrete in the plastic hinge zone will occur. } \\
\text { Spalling of cover concrete, such that longitudinal and transverse } \\
\text { reinforcement is visible, will occur. Shear deformations will become } \\
\text { more apparent. }\end{array}$ \\
\hline Collapse & $\begin{array}{l}\text { Spalling of concrete will continue such that a distance of } \\
\text { approximately 0.5h from the face of the beam-column joint will be } \\
\text { without cover concrete. Buckling of the longitudinal reinforcement } \\
\text { will be evident at this damage level. Rupture of longitudinal } \\
\text { reinforcement may occur }\end{array}$ \\
\hline
\end{tabular}

of $\beta$ calculated from Eq. 8 was equal to 0.08 , and was used throughout this study. After testing, this value was reset to 0.10 (results not reported here), based on a recommendation made by Kunnath et al. (1992) in their report on the computer programme IDARC. This resulted in the Park and Ang index returning values corresponding to the collapse damage state for six of the seven laboratory procedures. The exception was bidirectional cycling at ductility 8 but, as mentioned previously, this was due to the formation of the Park and Ang index not being based on low-cycle fatigue of reinforced concrete members. Thus, it is recommended that the value for $\beta$ be set equal to 0.10 for future studies.

Overall, damage indices provide a reasonable means of comparing experimental results derived from testing using different loading regimes. The advantage of calculating damage indices is that behaviour of the test subassemblage at intermediate stages of the test can be compared. In contrast, other criteria such as strength loss can only be applied to establish when failure of the test subassemblage occurs.

The ability of damage indices to facilitate comparison of experimental results at intermediate stages is shown in Fig. 12-a plot of the Park and Ang damage index for the tests where failure occurred. For example, a moderate damage level can be established for each test, which enables comparison of experimental data recorded at this stage of testing. This removes any problems associated with comparing data at a common ductility level because, as Fig. 12 clearly indicates, the behaviour of the test specimen is not consistent with the ductility level.

However, one weakness of damage indices is that the criteria for each damage level are extremely broad. Therefore, on the basis of the behaviour observed during this experimental study the descriptions listed in Table 7 have been expanded and the updated criteria are presented in Table 8.

Table 8 specifies the extent of cracking defined for each classification level and provides more indicators of severe damage and failure of the test specimen; for example, shear deformations becoming more apparent.

\section{CONCLUSIONS}

Displacement, ductility and drift are not sufficiently independent of loading history to be effective performance descriptors.

Dissipated energy is not sufficiently independent of loading history to be used as a performance descriptor.

Visible damage is not sufficiently quantifiable or repeatable to be used as a performance descriptor, but is used to describe damage levels.

Damage indices may be effective performance descriptors. Indices that consider both displacement and dissipated energy appear to be the most effective performance descriptors.

The Park and Ang index best described measured and observed performance.

To ensure that failure would occur prior to test conclusion, the Bracci index and the Park and Ang index need to provide values approximately equal to 1.1 .

\section{REFERENCES}

Applied Technology Council. (1989). "Procedures for Post-earthquake Safety Evaluation of Buildings." Report ATC-20.

Banon, H., and Veneziano, D. (1982) "Seismic Safety of Reinforced Concrete Members and Structures" Earthquake Engineering and Structural Dynamics, 10, pp. 179-193.

Bracci, J. M., Reinhorn, A. M., Mander, J. B., and Kunnath, S. K. (1989) "Deterministic Model for Seismic Damage Evaluation of Reinforced Concrete Structures" Technical Report NCEER, 89-0033.

Carr, A. J. (1998) "Ruaumoko-Program for Inelastic Dynamic Analysis", Dept. of Civil Engineering, University of Canterbury.

Cosenza, E., Manfredi, G., and Ramasco, R. (1993) "The Use of Damage Functionals in Earthquake Engineering: A Comparison Between Different Methods" Earthquake Engineering and Structural Dynamics, 22, pp. 855-868.

Darwin, D., and Nmai, C. (1986) "Energy Dissipation in RC Beams Under Cyclic Load" ASCE Journal of Structural Engineering, 112(8), pp. 1829-1846.

Emori, K., and Schnobrich, W. C. (1978) "Analysis of Reinforced Concrete Frame-Wall Structures for Strong Motion Earthquakes", Civil Engineering Studies, Structural Research Series No. 434, University of Illinois, Urbana, Illinois. 
Fang, I.-K., Wang, C.-S., and Hong, K.-L. (1994). "Cyclic Behaviour of High Strength Concrete Short Beams with Lower Amount of Flexural Reinforcement." ACI Structural Journal, 91(1), pp. 10-18.

Gosain, N. K., Brown, R. H., and Jirsa, J. O. (1977) "Shear Requirements for Load Reversals on RC Members" ASCE Journal of the Structural Division, 103(ST7), pp. 1461-1476.

Hwang, T. H., and Scribner, M. (1984) "RC Member Cyclic Response During Various Loadings" ASCE Journal of Structural Engineering, 110(3), pp. 477489.

Ingham J. M., Liddell, D., and Davidson, B. J. (2001) "Influence of Loading History on the Response of a Reinforced Concrete Beam" Bulletin of the New Zealand National Society of Earthquake Engineering, 34(2), pp. 107-124.

Kawashima, K. (1994) "Seismic Design Force of Bridges" Proceedings of the Second International Workshop on Seismic Design and Retrofitting of Reinforced Concrete Bridges, pp. 25-56.

Kinugasa, H., and Nomura, S. (1992) "Characteristics of Fatigue Damage for Reinforced Concrete Beams Under Reversed Loading" 10th World Conference on Earthquake Engineering, Madrid, Spain, 6, pp. 30833088.

Krawinkler, H. (1996) "Cyclic Loading Histories for Seismic Experimentation on Structural Components" Earthquake Spectra, 12(1), pp. 1-12.

Kunnath, S. K., El-Bahy, A., Taylor, A., and Stone, W. (1997) "Cumulative Seismic Damage of Reinforced Concrete Walls Under Load Reversals" Technical Report NCEER, 97-0006.

Kunnath, S. K., Reinhorn, A. M., and Lobo, R. F. (1992). "IDARC Version 3.0: A Program for the Inelastic Damage Analysis of Reinforced Concrete Structures." Technical Report NCEER, 92-0022.

Lefas, I. D., and Kotsovos, M. D. (1990) "Strength and Deformation Characteristics of Reinforced Concrete Walls Under Load Reversals" ACI Structural Journal, 87(6), pp. 716-726.

Leon, R. T., and Deierlein, G. G. (1996) “Considerations for the Use of Quasi-Static Testing" Earthquake Spectra, 12(1), pp. 87-110.

Liddell, D. (2000) "Influence of Loading History on Ultimate Displacement of Concrete Structures", ME Thesis, Department of Civil and Resource Engineering, University of Auckland.
Mander, J. B., and Dutta, A. (1998). "Capacity Design and Fatigue Analysis of Confined Concrete Columns." Technical Report - MCEER, 98-0007.

Park, R. (1989) "Evaluation of Ductility of Structures and Structural Assemblages from Laboratory Testing" Bulletin of the New Zealand National Society of Earthquake Engineering, 22(3), pp. 155-166.

Park, Y.-J., and Ang, A. H.-S. (1985) "Mechanistic Seismic Damage Model for Reinforced Concrete" ASCE Journal of Structural Engineering, 111(4), pp. 722-739.

Paulay, T., and Priestley, M. J. N. (1992) "Seismic Design of Reinforced Concrete and Masonry Buildings" John Wiley and Sons Ltd, New York, $744 p$.

Porter, M. L., and Tremel, P. M. (1987) "Sequential Phased Displacement Procedure for TCCMAR Testing" Third Meeting of the Joint Technical Coordinating Committee on Masonry Research, USJapan Coordinated Earthquake Research Program, Sapporo, Japan.

Powell, G. H., and Allahabai, R. (1988) "Seismic Damage Prediction by Deterministic Methods: Concepts and Procedures" Earthquake Engineering and Structural Dynamics, 16, pp. 719-734.

Roufaiel, M. S. L., and Meyer, C. (1987) "Analytical Modeling of Hysteretic Behavior of R/C Frames" Journal of Structural Engineering, ASCE, 113(3), pp. 429-444.

Scribner, C. F., and Wight, J. K. (1980). "Strength Decay in Reinforced Concrete Beams Under Load Reversals." ASCE Journal of the Structural Division, 106(ST4), pp. 861-875.

Shimazu, T., and Mollick, A. A. (1991) "Vertical LoadCarrying Capacity of Continuous Columns in Multistorey Reinforced Concrete Frames Subjected to Lateral Loading Reversals" ACI Structural Journal, 88(3), pp. 359-370.

Takeda, T., Sozen, M. A., and Nielsen, N. N. (1970). "Reinforced Concrete Responses to Simulated Earthquakes." Journal of the Structural Division, ASCE, 96(ST12), pp. 2557-2573.

Tomazevic, M., and Lutman, M. (1996). "Seismic Behaviour of Masonry Walls: Modeling of Hysteretic Rules." ASCE Journal of Structural Engineering, 122(9), pp. 1049-1054.

Tomazevic, M., Lutman, M., and Petkovic, L. (1996). "Seismic Behaviour of Masonry Walls: Experimental Simulation." ASCE Journal of Structural Engineering, 122(9), pp. 1040-1047. 
Williams, M. S., and Sexsmith, R. G. (1995). "Seismic Damage Indices for Concrete Structures: A State-ofthe-Art Review." Earthquake Spectra, 11(2), pp. 319349.

Williams, M. S., Villemure, I., and Sexsmith, R. G. (1997). "Evaluation of Seismic Damage Indices for Concrete Elements Loaded in Combined Shear and Flexure." ACI Structural Journal, 94(3), pp. 315-322. 